\title{
Inconclusive HIV-1/2 Results: How Far Should Blood Centers Go?
}

Eric Bassetti-Soares, Cristiane A. Andrade, Maria Virgínia C. Lima-Martins, Alcione M. de Pinho, Ester Barezani and Anna Bárbara F. Carneiro-Proietti

Testing of donated blood for blood transmittable diseases started in 1971, with hepatitis B surface antigen (HBsAg). The first blood-screening test to detect HIV was licensed in 1985, and was quickly implemented by blood banks to ensure safety of the blood supply and protect transfusion recipients [1].

Testing for transfusion transmittable infections in low prevalence populations tends to produce low positive predictive values [2]. The choice of a high or a low cut-off level for screening depends therefore on the relative importance we attach to false positive and false negative results [3]. Blood donors who test reactive (repeatedly or not) on enzyme immunoassay (EIA) and are not confirmed as positive are an ongoing problem for blood collection centers. Reactive units are discarded, although donors may be uncontaminated with the infectious agents [4].

Until recently, HIV-1/2 testing in blood centers in Brazil was done with one screening test, usually EIA, which was supplemented with other test, if repeatedly reactive. At Fundação Hemominas, Minas Gerais State Blood Center, a donor with only one out of three reactive HIV-1/2 ELISA (HIV-1 and 2, $3^{\text {rd }}$ Generation Plus EIA, Abbott, USA), done in the same blood sample, that is, not repeatedly reactive, had his donated blood discarded, without being further tested and was considered ineligible for future

Received on 27 November 2000; revised 17 March 2001. Address for correspondence: Dr. Anna Bárbara F. CarneiroProietti. Fundação Hemominas/ Presidência - Rua Domingos Vieira, 319 Segundo andar, Belo Horizonte, MG, Zip code: 30150-240. Phone: (31) 3248-4490. Fax: (31) 241-6415.

E-mail: annaproietti@usa.net/presid@hemominas.mg.gov.br

The Brazilian Journal of Infectious Diseases 2001;5(3):161(c) 2001 by The Brazilian Journal of Infectious Diseases and Contexto Publishing. All rights reserved.

$1413-8670$
Hemominas Foundation, Belo Horizonte, Brazil

donations. Counseling these donors was extremely difficult and doubt remained about their real HIV infection status.

The present study was conducted to establish the rate of HIV 1/2 seropositivity (EIA) among those donors, who had been rejected from donation, i.e., donors with only one reactive EIA to HIV-1/2. We have performed serological, clinical and epidemiological reappraisal in these individuals, aiming to define their true HIV serological status and to reintegrate to the eligible blood donor pool the individuals who proved negative.

Of the 665 donors fulfilling these criteria and invited by letter to participate in the study, 257 (38.6\%) accepted and 210 of these $(81.7 \%)$ completed the study protocol.

The donors completed a questionnaire designed to identify risky situations or behaviors to HIV $1 / 2$ infection and a clinical evaluation was done. Laboratory retesting included blood counts, erythrocyte sedimentation rate (ESR) and all the serologic tests required in Brazil to test blood donations $[4,5]$.

Of the 210 completing the study, 167 (79.5\%) were males and $43(20.5 \%)$ were females. The proportion of males was higher than that for the donor pool of the period $(\mathrm{n}=447,008)\left(\mathrm{Chi}^{2} 4.04, \mathrm{p}=0.044\right)$. The mean age was 36.1 years (range 19-67), and more than half were married $(57.0 \%, \mathrm{p}=0.12)$. Of the donors screened, 162/210 (77.14\%) had all tests negative. Both physicians and social workers interviewed the donors, to elicit reports of risk factors. By each interviewer the same rate of eligibility (63\%) was identified; $132 / 209$ by personal medical interview and $116 / 183$ when screening was done the social worker. The main cause of ineligibility based on the interview was promiscuous sexual behavior, reported by $30 / 77$ (39\%) to the physicians and by $38 / 67$ by $(57 \%)$ to the 
Table 1. Serologic and hepatic enzymes elevations in voluntary blood donors with inconclusive anti-HIV-1/2

\begin{tabular}{lcc}
\hline Test & $\begin{array}{c}\text { Number(\%) } \\
\text { reactive }\end{array}$ & $\begin{array}{c}\text { Number(\%) } \\
\text { indeterminate }\end{array}$ \\
\hline Anti-HIV 1/2 & $4(1.9 \%)$ & $6(2.9 \%)$ \\
Anti-HTLV I/II & 0 & 0 \\
Anti-HCV & $4(1.9 \%)$ & 0 \\
HbsAg & 0 & 0 \\
Anti-HBc & $29(13.8 \%)$ & 0 \\
ALT elevated & $4(1.9 \%)$ & 0 \\
Chagas' Disease & 0 & 0 \\
Syphilis & $9(4.3 \%)$ & 0 \\
\hline
\end{tabular}

social worker. In our experience, when interviewed after knowing they were ineligible as blood donors, individuals tended to be more honest about their sexual behavior. This could explain the more elevated report of high-risk sexual behavior during this research associated interview, but not when first presenting to donate blood.

The number of donors with positive serologic results and elevated hepatic enzymes are shown in Table 1. Among the sexually promiscuous, $5 / 44$ had hepatitis B core antibody (anti-HBc), 2/44 had increase in the ALT levels and the same number had serological syphilis. From 11 reporting alcohol addicting, 2 showed increased ALT levels, one had positive anti-HBc serology and one had an inconclusive serology for HIV $1 / 2$. From the three IV drug users, one showed reactive results for syphilis and both hepatitis B and C. Among five reporting homosexual practices, one had serology positive for syphilis, hepatitis B and HIV-1/12 and another one for hepatitis B.

The number of individuals reintroduced to the blood donor pool was 104/210 (50\%). Our reevaluation showed that $10(5 \%)$ of the 106 rejected donors were also ineligible due to the serology for HIV. We concluded that it was possible to reintegrate approximately half of candidates to the blood donor pool, following a repeat interview and serological reevaluation.

\section{Acknowledgements}

The authors would like to thank Claudia M. Ribeiro, Eva Passaglia, Verônica Santos, Maria C. A. Miranda, Aparecida Q. R. Silva, Cristina M. Sartini and Cybele G. Chaves for their participation in this work.

\section{References}

1. CDC. Public Health Service guidelines for counseling and antibody testing to prevent HIV infection and AIDS. MMWR 1987;36:509-15.

2. Dodd R.Y., Stramer S.L. Indeterminate results in blood donor testing: what you don't know can hurt you. Transfusion Medicine Reviews 2000;14:151-60.

3. Gordis L. Epidemiology. Pennsylvania, USA: W.B. Sanders Company, 1996.

4. Ownby H.E., Korelitz J.J, Busch M.P., et al. Loss of volunteer blood donors because of unconfirmed enzyme immunoassay screening results. Retrovirus Epidemiology Donor Study. Transfusion 1997:37:199-205.

5. Ministério da Saúde, Brasil, Portaria n.1376. Diário Oficial da União 1993;229:18405.

6. Ministério da Saúde, Brasil Portaria n.2135. Diário Oficial da União 1994;244:20526. 